\title{
Anthropometric analysis of the eyeball exposure area in Koreans
}

\author{
Ki Soo Park, Soon Il Ka, Dae Hwan Park \\ Department of Plastic and Reconstructive Surgery, Catholic University of Daegu School of Medicine, Daegu, Korea
}

Background Eyelids vary in morphology and structure depending on age, sex, and race. Usually, one-dimensional measurements are used to evaluate blepharoplasty outcomes. However, in recent years, three- or four- directional enlargements of the eyelid have been used for blepharoplasty in Asian patients, and the outcomes of techniques such as lateral canthoplasty or canthotomy and medial epicanthoplasty with increased scleral area cannot be analyzed using marginal reflex distance 1 or the area of corneal exposure. Therefore, we describe the use of a measurement method based on the eyeball exposure area (EEA).

Methods To obtain normal EEA values by age and sex, 320 individuals were recruited. The participants were divided into eight age groups $(n=40$ in each group: female subjects, $n=20$; male subjects, $n=20$ ): $10-19,20-29,30-39,40-49,50-59,60-69,70-79$, and 80-89 years. The EEA value was obtained by dividing the exposed area by the total eyeball area. The normal EEA values and differences in EEA according to age and sex were calculated.

Results The mean EEA values for male and female subjects were $66.86 \% \pm 9.20 \%$ and $71.48 \% \pm 10.48 \%$, respectively. In each age group, the EEA values of females were higher than those of males. EEA decreased significantly with age in both male and female subjects $(\mathrm{P}<0.05)$.

Conclusions We determined normal EEA values according to age and sex. EEA can be used as an indicator of the outcome of blepharoplasty.

Keywords Anthropometric / Eyelids / Database
Correspondence: Dae Hwan Park Department of Plastic and Reconstructive Surgery, Catholic University of Daegu School of Medicine, 33 Duryugongwon-ro 17-gil, Nam-gu, Daegu 42472, Korea Tel: +82-53-650-4581

Fax: -82-53-650-4584

E-mail:dhpark@cu.ac.kr

Received: September 8, $2019 \bullet$ Revised: January 6, 2020 - Accepted: January 9, 2020

pISSN: 2234-6163 • elSSN: 2234-6171 • https://doi.org/10.5999/aps.2019.01200 • Arch Plast Surg 2020;47:9-14

\section{INTRODUCTION}

Eyelids vary in morphology and structure depending on age, sex, and race [1]. A number of anthropometric studies on the eyelids of African-Americans have been published [2,3], but no studies have been conducted on eyelid measurements in Asian populations.

Several methods are available to analyze outcomes after blepharoplasty. The parameters commonly measured in these meth- ods include symmetry, double-fold height, marginal reflex distance (MRD), vertical height of the palpebral fissure, and marginal limbal distance [4-6]. However, these indicators are onedimensional measurements that involve only distance. Such one-dimensional measurements have limitations for measuring the overall increase in the ocular surface area.

The features of eyelids in Asian populations include a single fold, a narrow fissure, a downward cornea, and a wide intercanthal distance. Due to these features, Asians have smaller eyes 
than those of Westerners. Therefore, Asian patients may wish to increase the perceived size of their eyes through eye surgery. In such cases, surgery to increase the overall eye size in three or four directions (superior, inferior, medial, and lateral) is preferred. In upper blepharoplasty with or without ptosis correction and lowering of the lower lid, the postoperative outcome can be evaluated using measurements such as MRD 1 (MRD1) and area of corneal exposure (ACE). However, in lateral canthoplasty or canthotomy and medial epicanthoplasty with increased scleral area, it is difficult to measure postoperative results using MRD1 or ACE. Patients who undergo these surgical procedures have their eyes enlarged vertically, medially, and laterally. In these patients, simply measuring the length or corneal exposure area of the eye is not appropriate for the evaluation of postoperative outcomes, as such measurements cannot fully reflect the increase in the overall ocular surface area after surgery. In a previous study, researchers used ACE as a two-dimensional measure [7]. However, various factors, such as the distance and angle, affect the accuracy of this type of measurement on patient images. In addition, ACE does not reflect an increase in the overall size of the eye, including the sclera. Therefore, we designed the use of an alternative measurement method based on the eyeball exposure area (EEA), which is derived by dividing the exposed area by the total eyeball area. Since no study has been conducted regarding normal EEA values in Koreans, we desired to measure this parameter to assist in the clinical application of EEA values.

\section{METHODS}

\section{Study group}

In total, 320 participants were enrolled. Patients who had previously undergone blepharoplasty or who had a history of trauma around the eye were excluded. The participants were divided into eight age groups ( $\mathrm{n}=40$ in each group: female subjects, $\mathrm{n}=20$; male subjects, $\mathrm{n}=20$ ): 10-19, 20-29, 30-39, 40-49, $50-59,60-69,70-79$, and $80-89$ years. This study was approved by the Bioethics Committee of the Daegu Catholic University Medical Center under Institutional Review Board protocol CR-19-143. This study conformed to the ethical principles for medical research set forth by the Declaration of Helsinki.

\section{Anthropometric and photographic analysis}

Normal EEA values and differences in EEA according to age and sex were determined. First, the total eyeball area (Fig. 1A) and then the exposed eyeball area (Fig. 1B) were measured. The EEA value, as a percentage, was obtained by dividing exposed eyeball area by total eyeball area. After displaying the area using Adobe Photoshop CS3 software (Adobe, San Jose, CA, USA), the measured area was numerically calculated using a Java-based image processing program (Image 1.40; National Institutes of Health, Bethesda, MD, USA), and the EEA was determined (Fig. 2). The same individual obtained and processed all of the photographic images.

\section{Statistical analysis}

SPSS version 25 (IBM Corp., Armonk, NY, USA) was used to analyze the data. One-way analysis of variance and the independent-samples t-test were used. A P-value of $<0.05$ was considered to indicate statistical significance.

\section{RESULTS}

The EEA values of younger participants were higher than those of older subjects (Fig. 3). The EEA values were $79.09 \% \pm 4.81 \%$ and $86.84 \% \pm 2.92 \%$ for males and females, respectively, in the $10-19$ years group and gradually decreased to $53.56 \% \pm 2.47 \%$ and $56.98 \% \pm 3.10 \%$ for men and women, respectively, in the

\section{Fig. 1. Eyeball exposure area}

(A) Simulation of the exposed corneal and scleral area, showing the lower lid margin at the lowest margin of the limbus and the upper lid margin at the highest margin of the limbus. (B) Exposed corneal and scleral area. 


\section{Fig. 2. Measurements of the eyeball exposure area}

Measurements of eyeball exposure area obtained using Adobe Photoshop CS3 software and a Java-based image processing program. Display of the area using Adobe Photoshop CS3 software. Total eyeball area (A) and exposed eyeball area (B).
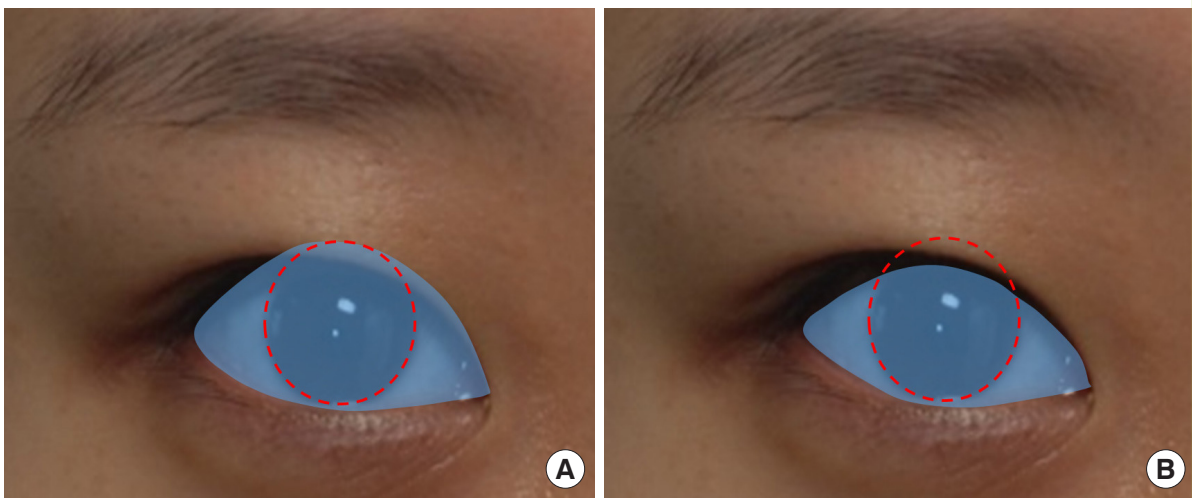

\section{Fig. 3. Eyeball exposure area according to age}

Eyeball exposure area (EEA) was measured in an 18-year-old woman (A) and an 81-year-old woman (B). The EEA of the younger woman was 86\% on the right side and $87 \%$ on left side. The EEA of the older woman was 52\% on the right side and 51\% on the left side. As such, the EEA of the younger woman was greater than that of the older woman.

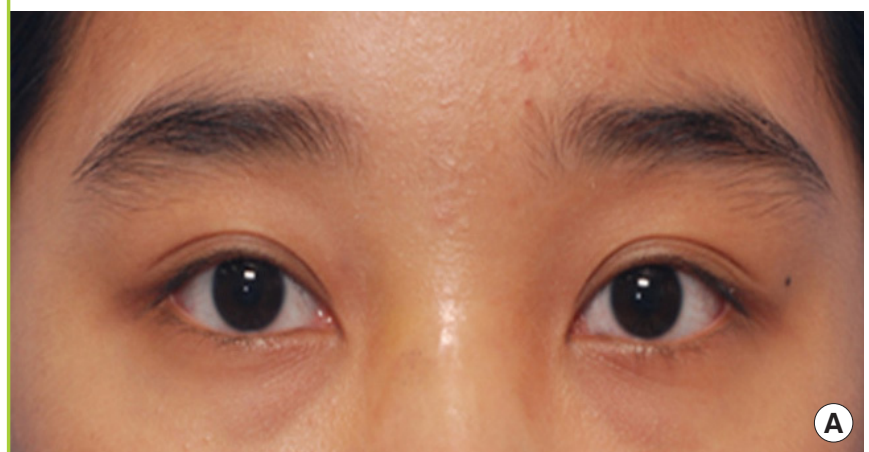

Table 1. Eyeball exposure area according to age and sex

\begin{tabular}{|lcc|}
\hline Age $(\mathrm{yr})$ & Female sex $(\%)$ & Male sex $(\%)$ \\
\hline $10-19$ & $86.84 \pm 2.92$ & $79.09 \pm 4.81$ \\
$20-29$ & $82.72 \pm 4.96$ & $75.31 \pm 3.54$ \\
$30-39$ & $77.36 \pm 3.31$ & $73.68 \pm 2.31$ \\
$40-49$ & $73.07 \pm 1.96$ & $69.75 \pm 2.69$ \\
$50-59$ & $69.84 \pm 1.75$ & $65.50 \pm 2.10$ \\
$60-69$ & $64.28 \pm 4.55$ & $60.90 \pm 4.79$ \\
$70-79$ & $60.75 \pm 4.33$ & $57.08 \pm 3.18$ \\
$80-89$ & $56.98 \pm 3.10$ & $53.56 \pm 2.47$ \\
Total & $71.48 \pm 10.48$ & $66.86 \pm 9.20$ \\
\hline Values are presented as mean $\pm S D$. Each group has 40 participants: female \\
subjects $(\mathrm{n}=20)$ and male subjects $(\mathrm{n}=20)$.
\end{tabular}

80-89 years group (Table 1 ). The EEA values significantly differed according to age $(\mathrm{P}<0.05)$. The greatest decrease in EEA was observed between ages 50-59 years and 60-69 years (Table 2). Overall, patient age and EEA were negatively correlated $\left(\mathrm{R}^{2}=0.807\right)$. The relationship between EEA and age was explained by the following formula: EEA $=-0.401 \times$ age +88.704 .

For all age groups, the EEA values of female subjects were

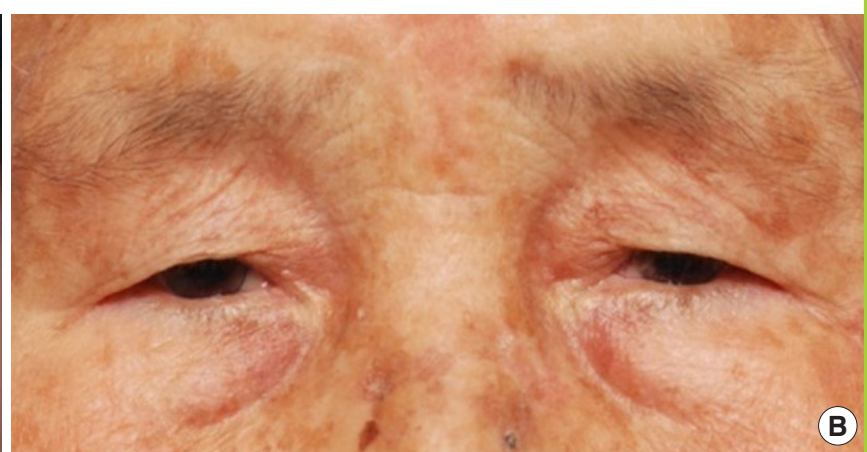

Table 2. Changes in EEA according to age

\begin{tabular}{|c|c|c|}
\hline Age $(y r)$ & EEA (\%) & $\begin{array}{l}\text { Difference between the specified } \\
\text { and previous age group (\%) }\end{array}$ \\
\hline $10-19$ & $82.97 \pm 5.55^{\text {a) }}$ & - \\
\hline $20-29$ & $79.01 \pm 5.68^{\mathrm{a})}$ & 3.96 \\
\hline $30-39$ & $75.52 \pm 3.39^{\mathrm{a})}$ & 3.49 \\
\hline $40-49$ & $71.41 \pm 2.88^{a)}$ & 4.11 \\
\hline $50-59$ & $67.67 \pm 2.91^{\mathrm{a})}$ & 3.74 \\
\hline $60-69$ & $62.59 \pm 4.97^{a)}$ & 5.08 \\
\hline $70-79$ & $58.91 \pm 4.22^{\mathrm{a})}$ & 3.67 \\
\hline $80-89$ & $55.27 \pm 3.28^{a)}$ & 3.65 \\
\hline Total & $69.17 \pm 10.13$ & - \\
\hline \multicolumn{3}{|c|}{$\begin{array}{l}\text { Values are presented as mean } \pm \mathrm{SD} \text {. Each group has } 40 \text { participants. } \\
\text { EEA, eyeball exposure area. } \\
\text { Statistical analyses of multiple groups were performed using one-way analysis of } \\
\text { variance followed by the Bonferroni post-test. }{ }^{\text {al }} P<0.05 \text {, constituting a significant } \\
\text { difference between the age groups. }\end{array}$} \\
\hline
\end{tabular}

higher than those of male subjects (Fig. 4). The mean EEA value was $66.86 \% \pm 9.20 \%$ for males and $71.48 \% \pm 10.48 \%$ for females. EEA significantly differed according to sex in each age group (Fig. 5). 


\section{Fig. 4. Eyeball exposure area according to sex}

Eyeball exposure area (EEA) was measured in a 22-year-old woman (A) and a 22-year-old man (B). The EEA of the woman was 89\% on the right side and $88 \%$ on the left side. The EEA of the man was 78\% on the right side and $80 \%$ on the left side. As such, the EEA of the woman was greater than that that of the man of the same age.
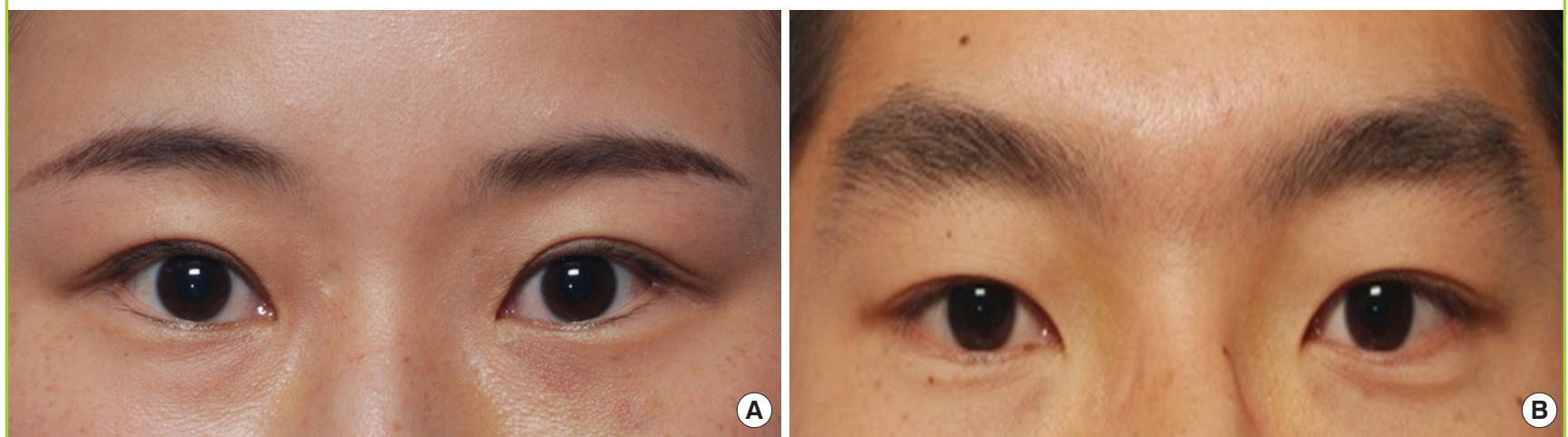

\section{Fig. 5. Eyeball exposure area according to sex}

The eyeball exposure area (EEV) values of female subjects were higher than those of male subjects. A significant difference in EEV according to sex $(P<0.05)$ was observed.

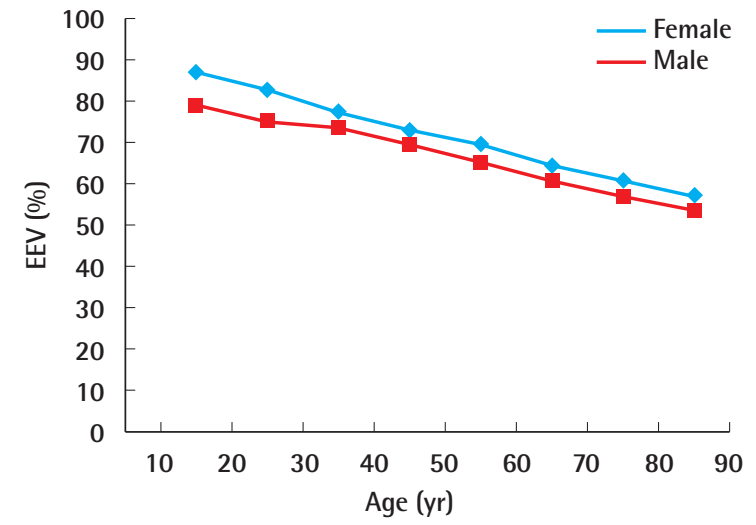

\section{DISCUSSION}

Plastic surgeons try to reduce complications, improve surgical outcomes, and enhance patient satisfaction after blepharoplasty. A comparison of preoperative and postoperative appearance using objective indicators is very important for evaluating surgical outcomes. Various measurements can be used to make such comparisons [1,8-12]. These include measurements of the palpebral fissure, which are used to assess outcomes after upper blepharoplasty [5]. However, the palpebral fissure varies widely in morphology and structure depending on age and race [5].

Postsurgical measurements are usually acquired through a photogrammetric study of patient photographs. Milbratz et al. [13] used a software program to measure multiple radial midpupil lid distances. Bae et al. [14] performed a photogrammet- ric study of the eyes of Korean youths. Song et al. [15] used standardized photographs to analyze the metric and nonmetric characteristics of Korean eyes. However, these types of measurements are often inaccurate, and errors can arise due to the angle of photography, the location where the image was taken, the size of the image, the distance between the patient and the camera, and the proficiency of the photographer. In addition, these are all one-dimensional measurements, which cannot provide adequate information on the postoperative outcomes of three- or four-directional surgery. Park et al. [7] used a two-dimensional measure, the fraction of corneal exposure in the eye. However, considering only the corneal area of the eye can limit the accuracy of measurements of changes in overall eye size following surgery [7]. For example, in cases of upper blepharoplasty with or without ptosis correction and lowering of the lower lid, the surgical results can be analyzed using ACE or MRD1. However, in cases of lateral canthoplasty or canthotomy and medial epicanthoplasty with increased scleral area, the surgical results cannot be analyzed using these measurements.

Therefore, in our study, we used a digital photographic technique and the EEA value, which represents a fraction of the total eyeball area, including the area of the sclera. EEA measures area, which is a simple measurement to obtain, instead of distance. The measured value is displayed as a percentage, and the value is not affected by factors such as the distance at which the image is obtained or the size of the image. Thus, it offers a convenient and accurate eyelid measurement method.

Furthermore, the area can be a more accurate measurement of changes in the eyes. For example, van den Bosch et al. [16] found no statistically significant decrease in the MRD with age. In contrast, EEA declined with age in our study. This discrepancy is likely due to the fact that EEA represents not a one-dimensional distance, but rather a two-dimensional measurement of 
area that is similar to the corneal exposure area in Koreans [7]. Duke-Elder and Wybar [17] found that globe size did not vary with age in adults. Thus, with regard to the calculation of EEA, the total area of the eyeball does not change with age, but the exposed eyeball area decreases. Lower lid laxity increases with age, and ptosis can occur in older people. Direk et al. [18] demonstrated that the palpebral fissure area significantly decreases with age. This finding is consistent with the observed decrease in EEA with age in our study.

In this study, we describe the use of EEA, which is calculated as a fraction of two-dimensional area measurements-including the area of the sclera-rather than a simple, one-dimensional distance measurement. EEA is easy to measure and is not affected by factors such as the distance at which an image is obtained or the size of the image. EEA data can aid in understanding normal eyelid measurements according to age and sex.

Recently, three- and four-directional surgery, including medial and lateral canthoplasty, has been performed. Therefore, it is very important to measure the overall increase in size of the eye, including the sclera, in order to accurately assess the results of these procedures. Measurements of EEA can be useful for postoperative evaluations of patients after blepharoplasty and can serve as indicators of surgical success. In the future, further studies should be conducted to assess the difference in EEA between patients with natural double folds and those with single folds in the same age group. To facilitate the clinical application of EEA, it will also be important to study in greater depth how EEA varies according to age.

\section{NOTES}

\section{Conflict of interest}

No potential conflict of interest relevant to this article was reported.

\section{Ethical approval}

The study was approved by the Institutional Review Board of Daegu Catholic University Medical Center (IRB No. CR-19143) and performed in accordance with the principles of the Declaration of Helsinki. Written informed consents were obtained.

\section{Patient consent}

The patients provided written informed consent for the publication and the use of their images.

\section{Author contribution}

Conceptualization: Park KS, Ka SI, Park DH. Data curation:
Park KS, Ka SI, Park DH. Formal analysis: Park KS, Ka SI, Park DH. Methodology: Park KS, Ka SI, Park DH. Project administration: Park KS, Ka SI, Park DH. Visualization: Park KS, Ka SI, Park DH. Writing - original draft and review \& editing: all authors.

\section{ORCID}

Ki Soo Park https://orcid.org/0000-0002-0243-932X

Soon Il Ka https://orcid.org/0000-0001-5798-5179

Dae Hwan Park https://orcid.org/0000-0001-9671-6510

\section{REFERENCES}

1. Park DH, Choi WS, Yoon SH, et al. Anthropometry of Asian eyelids by age. Plast Reconstr Surg 2008;121:1405-13.

2. Barretto RL, Mathog RH. Orbital measurement in black and white populations. Laryngoscope 1999;109(7 Pt 1):1051-4.

3. Farkas LG, Forrest CR, Litsas L. Revision of neoclassical facial canons in young adult Afro-Americans. Aesthetic Plast Surg 2000;24:179-84.

4. Price KM, Gupta PK, Woodward JA, et al. Eyebrow and eyelid dimensions: an anthropometric analysis of African Americans and Caucasians. Plast Reconstr Surg 2009;124: 615-23.

5. Baek SW, Kim JH, Park SH, et al. Anthropometric analysis of palpebral fissure. J Korean Soc Aesthetic Plast Surg 1995; 1:221-6.

6. Park DH, Jung JM, Song CH. Anthropometric analysis of levator muscle function. Plast Reconstr Surg 2008;121:11817.

7. Park K, Guo Z, Park DH. Measurement of the area of corneal exposure using digital image and its application during assessment for blepharoplasty. Aesthetic Plast Surg 2018;42: 208-14.

8. Song WS, Kim YH, Lee SJ. Morphologic study of upper eyelid contour and functional evaluation of levator palpebrae superioris muscle in adult and young people. J Korean Ophthalmol Soc 2001;42:1523-9.

9. Seo HY, Ahn HB. Morphological changes of the eyelid according to age. J Korean Ophthalmol Soc 2009;50:1461-7.

10. Park JJ, Hwang JH, Kim ES, et al. The relationship between the iris diameter, palpebral fissure width and intercanthal distance for beautiful eye. J Korean Soc Aesthetic Plast Surg 2007; 13:33-8.

11. Lee JS, Kim HK, Kim YW. Anthropometric analysis of the attractive and normal faces in Korean female. J Korean Soc Plast Reconstr Surg 2004;31:526-31.

12. Song CH, Ahn KY, Han DC, et al. The age-related anthro- 
pometric analysis of eyelids and orbits in Koreans. J Korean Soc Plast Reconstr Surg 1999;26:1131-7.

13. Milbratz GH, Garcia DM, Guimaraes FC, et al. Multiple radial midpupil lid distances: a simple method for lid contour analysis. Ophthalmology 2012;119:625-8.

14. Bae TH, Kim JC, Kim WS, et al. A photogrammetic study of the eyes in Korean youths. J Korean Soc Plast Reconstr Surg 2007;34:37-43.

15. Song WC, Park SH, Koh KS. Metric and non-metric characteristics of Korean eyes using satadardized photographs. Ko- rean J Phys Anthropol 2002;15:95-107.

16. van den Bosch WA, Leenders I, Mulder P. Topographic anatomy of the eyelids, and the effects of sex and age. Br J Ophthalmol 1999;83:347-52.

17. Duke-Elder S, Wybar KC. System of ophthalmology: the anatomy of the visual system, vol II. St. Louis: Mosby; 1961.

18. Direk FK, Deniz M, Uslu AI, et al. Anthropometric analysis of orbital region and age-related changes in adult women. J Craniofac Surg 2016;27:1579-82. 